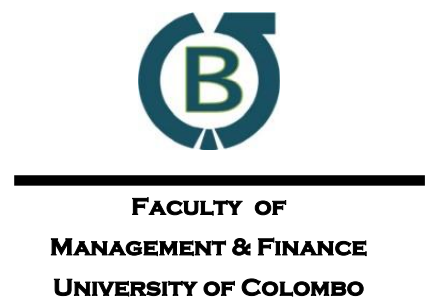

\title{
Boundaries and Borders: How Do Recipients Interpret Social- Sexual Behaviour at Work?
}

\author{
Arosha S. Adikarama ${ }^{a}$ \\ ${ }^{a}$ Department of Human Resources Management, University of Colombo, Sri Lanka
}

\begin{abstract}
This article aims to provide a conceptual framework for elucidating how and under what circumstances women interpret social-sexual behaviours they experience at work as sexual harassment, by reviewing journal articles related to the interpretation of sexual conduct and harassment published between 1990 and 2016. By appraising, expanding, synthesising and collating extant literature in the area, it is proposed that social-sexual behaviour experienced by women at the workplace will be interpreted as harassing or not depending on: a) how they perceive the appropriateness of the intentions of the harasser, b) their sensitivity to the issue of sexual harassment, c) how personally vulnerable they are, d) the context within which the behaviour occurred and c) the behaviour itself. The proposed framework adds to existing knowledge by building on and expanding the prior understanding of how social-sexual behaviour at work is interpreted, going beyond the constricted attention paid to one or few factors affecting interpretation in a piecemeal fashion.
\end{abstract}

Keywords: Sexual harassment at workplace, Social-sexual behaviour, Working women

Received:

10 May 2018
Accepted revised version:

30 October 2018
Published:

31 December 2018

Suggested citation: Adikaram, A.S. (2018). Boundaries and borders: How do recipients interpret social-sexual behaviour at work? Colombo Business Journal. (9)2, 77-101

DOI: http://doi.org/10.4038/cbj.v9i2.37

(C) 2018 The Authors. This work is licenced under a Creative Commons Attribution 4.0 International Licence which permits unrestricted use, distribution, and reproduction in any medium, provided the original work is properly cited.

$凶$ agamwarige@gmail.com: (iD https://orcid.org/0000-0002-2248-6035 


\section{Introduction}

Social-sexual behaviour at the workplace is a phenomenon that has gained much attention of scholars during the past few decades, especially in research and discussions related to sexual harassment. While the origin of sexual harassment would be a social-sexual behaviour, all such behaviours at work may not be sexual harassment (Lonsway, Paynich, \& Hall, 2013; Page, Pina, \& Giner-Sorolla, 2016). According to Aquino, Sheppard, Watkins, O'Reilly, and Smith (2014), social-sexual behaviours are

[the] workplace interactions occurring between two or more organisational members (including clients and customers) that are construed by the parties involved as having sexual connotations, but that are not necessarily perceived by one or more parties involved as having a threatening or harassing intent. (p. 10)

Hence, social-sexual behaviours can be seen as fun, pleasurable, enjoyable, (Aquino et al., 2014; Berdahl \& Aquino, 2009; Dellinger \& Williams, 2002; Denissen, 2010; Giuffre \& Williams, 1994; Schultz 1998), or as threatening, harassing or offensive. When these social-sexual behaviours are seen as harassing, threatening or offensive, they can be perceived as sexual harassment. Sexual harassment is defined as 'unwelcome sexual advances, requests for sexual favours and other verbal or physical conduct of a sexual nature' which affects the terms, conditions, or employment decisions related to an individual's job ('quid pro quo' harassment) or creates an 'intimidating, hostile, or offensive working environment' ('hostile environment' harassment) (Equal Employment Opportunity Commission Guidelines on Discrimination Because of Sex, 1999).

Yet, how these social-sexual behaviours become harassing to one person, not harassing to another, and enjoyed by yet another, remains a mystery even after decades of research (e.g. Gutek, Cohen, \& Konrad, 1983; Wiener \& Hurt, 2000). As O'Connor, Gutek, Stockdale, Geer, and Melancon (2004) and many others (e.g., Denissen, 2010) claim, interpreting sexual harassment is complex. According to Langhout et al. (2005), "it remains unclear how these social-sexual workplace behaviour translate into harm" (p. 976). It is this knowledge gap that the current review attempts to fill by drawing from past literature in the area, to develop a conceptual framework that will elucidate how and under what circumstances a recipient would construe a social-sexual behaviour as sexual harassment. Given the existence of gender difference in perceptions (Foulis \& McCabe, 1997; Gutek \& O'Conner, 1995; Hurt, Wiener, Russell, \& Mannen, 1999; Osman, 2007; Rotundo, Nguyen, \& Sackett, 2001), as well as the high prevalence of sexual harassment among 
women, this framework will focus on women recipients' interpretation of sexual conduct (the word sexual conduct is synonymously used with the word social-sexual behavior, with the same meaning) at work.

The importance of this framework is threefold. Firstly, the framework will provide useful guidelines for future researchers in preparing questionnaires, interview guides or vignettes for exploring the prevalence and perceptions of sexual harassment, by taking into consideration the many factors that contribute to the identification of sexual harassment. Secondly, this framework will specifically assist managers and complaint handlers of organisations to understand complaints related to sexual harassment from a recipient's subjective point of view. More specifically, this framework will illustrate why women feel harassed about certain social-sexual behaviour at work. This understanding will support managers to ascertain more effectively and equitably, whether sexual harassment has actually taken place. Moreover, this knowledge of interpretation can also be used in defining sexual harassment in anti-sexual harassment policies, in training programmes and in designing guidelines for complaint handlers.

Thirdly, this framework builds on and expands prior understanding of how social-sexual behaviour at work is interpreted (e.g. Gutek et al., 1983; Cortina \& Berdahl, 2008; Hunt Davidson, Fielden, \& Hoel, 2010; McDonald, 2012; Rotundo et al., 2001; Yagil, 2008). While prior research have attempted to understand the cognitive processes underlying the interpretation of sexual conduct at work by proposing various explanations, they do not capture the full complexity of the process nor the many factors that impact this interpretation as a whole. For example, Fitzgerald Swan, and Magley (1997) provide a framework, emphasising objective factors (having to do with behaviour itself such as frequency, intensity and duration of the behaviour), individual factors (having to do with individual women such as victimisation history, resources, attributes, attitudes and control) and contextual factors (having to do with the context within which the behaviour takes place such as organisational climate, management norms, policies, procedures, gender ratio and bystander stress). They have primarily looked at the influence of these factors on the subjective appraisal of the behviour leading to various outcomes. Studies have also looked at the person-situation interaction in appraising the severity of harassment (Langhout et al., 2005). Further, Stockdale, Logan, Sliter, and Berry (1995) summarised five general models or hypotheses to explain how individuals come to identify behaviours as being sexually harassing. This includes: type of experience, attribution, affect, organizational power, and personal characteristics. 
Yet, many of these studies exploring the concept has done so from an observer's perspective rather than from a recipient perspective (Barr, 1993; Bursik \& Gefter, 2011; O'Connor et al., 2004; Wiener \& Hurt, 2000; Wiener, Winter, Rogers, \& Arnot, 2004), or have overemphasised one or few factors affecting interpretaion at the cost of ignoring the totality and the complexity of the situation (with exceptions such as Bingham, 1994) and has tended to look at this in a piecemeal fashion (Gordon, Cohen, Grauer, \& Rogelberg, 2005). As Denissen (2010) affirms, "'[y]et a limitation of many studies that focus on interpretations of sexual conduct is that they do not fully analyse the process through which interpretations are formed" (p. 300). This review, therefore, specifically builds on and expands on the prior researchers' reviews and empirical work (e.g. Blumenthal, 1998; Cortina \& Berdahl, 2008; Hunt et al., 2010; McDonald, 2012; Rotundo et al., 2001; Yagil, 2008) by taking into consideration the many diverse factors and contexts discussed thus far only in a piecemeal fashion and often, fragmented and not systematically analysed - in order to elucidate the complex cognitive process of interpretation of sexual harassment. Further, the analysis will inform an area that is largely omitted in sexual harassment research, namely, the recipient's perspective, rather than the observer's (a person who observes somebody else being subjected to sexual conduct) perspective.

It is also important to note that by exploring how women recipients' interpret sexual conduct at work, I am in no way attempting to establish or contend that if a conduct is not interpreted as harassing by the recipient that it is not sexual harassment, or that other important elements of sexual harassment such as power does not play a role in the occurrence of sexual harassment. Rather, my intention here is to clarify the subjectivity surrounding sexual harassment by exploring how and under what circumstances women interpret social-sexual behaviours at work as sexual harassment, which has been a continuous debate especially in disciplines such as human resource management, phycology and law.

\section{Review Strategy}

Given the extent of the literature related to perceptions, attitudes, appraisals and interpretations of sexual harassment, I begin by clarifying the parameters of this review. Many past studies have explored how women interpret sexual harassment at the workplace under different terminologies. While some researchers have used the term 'judgment' (O'Connor et al., 2004), others have used 'evaluation' (Berdahl \& Aquino, 2009), 'tolerance' (Vogt, Bruce, Street, \& Stafford, 2007), 'sensitivity' (Crow, Hartman, Hammond, \& Fork, 1995), 'appraisal' (Langhout et al., 2005), 'sensemaking' (Dougherty \& Smythe, 2004), 'cognitive framework' (Fitzgerald et 
al., 1997), 'perceptions' and 'attitudes' towards sexual harassment (Barr, 1993; Bursik \& Gefter, 2011; Dougherty, Turban, Olson, Dwyer, \& Lapreze, 1996; Foulis $\&$ McCabe, 1997), as well as a combination of these terms synonymously (Pryor \& Day, 1988).

As the primary focus of this review is on how women 'interpret' sexual harassment, I draw mostly on sexual harassment research in the areas of interpretation, judgments, evaluation, perceptions and attitudes by looking at the factors and contexts that influence this interpretation. I do not review the considerable body of literature on sex, sexual conduct, sexuality and romance at the workplace and I do not attempt to understand what specific behaviours recipients think of as constituting sexual harassment, whether they label their experiences as sexual harassment or whether the interpretation is right or wrong. My attempt here is to develop a framework that explains how and in what circumstances a woman would interpret her experience of sexual conduct as harassing, and what factors would contribute to this interpretation. Further, I will be looking at the interpretation of the recipient and will not consider the position, attitudes and the interpretation of the perpetrator, as the inclusion of the perpetrator's position will bring in a contravening point of view and make the recipient's interpretation (and the framework) more complex and difficult to gauge.

Furthermore, clarification is needed on what is meant by 'interpretation of sexual conduct' in this article. According to Blanchette and Richards (2010), "interpretation is the process through which one meaning is extracted from ambiguous information in order to construct a mental representation" (p. 562). Stemming from this definition, I take interpretation of sexual harassment to mean the subjective cognitive process through which a person extracts meaning from ambiguous information regarding sexual conduct in order to construct a mental representation of sexual harassment. Also, in identifying the different ways women appraise a sexual conduct such as frightening, bothersome (Settles, Harrell, Buchanan, \& Yap, 2011), upsetting (Hitlan, Schneider, \& Walsh, 2006) and evoking other emotional responses such as fear, anxiety, and anger (Wright \& Fitzgerald, 2007), I use the umbrella term 'harassing' to encompass a range of interpretations, from feeling offended and uncomfortable to frightened.

Within this background, a thematic analysis (Braun \& Clarke, 2006) was carried out along the following eight steps: 
Step 1: An initial search for related articles was carried out using the major search engines such as Ebscohost and Google Scholar, as well as major databases of publishers such as Sage, Elsevier, Emerald, Springer, Wiley and JSTOR. The words 'sexual harassment' together with the search words 'perception', 'interpretation', and 'judgment' were employed for the search at this initial stage and only the articles published from 1990 to 2016 were selected.

Step 2: Unrelated articles such as non-workplace sexual harassment (such as in the academia and in transport) were excluded (however, articles addressing the academia as a workplace was considered) and certain studies on observer judgment (e.g. Wiener et al., 2004), the findings of which could not be linked to recipeint interpretations, were also excluded.

Step 3: Based on the articles selected through the initial search, more relevant literature was identified and accessed through the snowball sampling technique by referring the list of references of the identified articles to broaden the initial review, again with the key search terms ('sexual harassment' together with the search words 'perception', 'interpretation', and 'judgment') in mind.

Step 4: Through a review of this initial set of articles, intial codes were generated (priori codes as well as inductive codes) which captured factors that affect the interpretation of sexual harassment. Some such initial codes generated were: prior socialisation between the harasser and the recipient, gender of the recipient, marital status of the recipient, and marital status of the perpetrator.

Step 5: Then, more articles were selected for the review using these initial codes as the search words. Simultaneously, similar to stage 3, more relevant literature related to these intial codes were identified and accessed through the snowball sampling technique by referring the list of references of the initally identified articles. This assisted not only in establishing the aruguments, but also in broadening the review.

Step 6: Within this iterative process of analysis and search for relevant articles, certain initial codes (factors) identified were eliminated owing to insufficient prior research or information. For example, factors such as explicitness of sexual interest (Solomon \& Williams, 1997), sexual orientation (Hendrix, 2000), perceiving or experiencing negative consequences for rejection (Settles et al., 2011), behaviour occurring in a work setting as against a social setting (Dougherty et al., 1996), the educational status of the recipient (Maeder, Wiener, \& Winter, 2007; Pickerill, Jackson, \& Newman, 2006), attractiveness of the recipient (Bluemental, 1998) were eliminated in the 
process. The initial codes where a clear link between the code (factor) and the interpretation of sexual conduct could be established and where sufficient literature / information was available to support the arguments / relationships were further developed, explored and considered for the development of the framework.

Step 7: These initial codes were then synthesisd into braoder analytical themes (Thomas \& Harden, 2008), based on the similarities and differences, for a broader and deeper explanation. These themes were then named and explained with the relationships being well developed. For example, the concepts of prior socialisation between the harasser and the recipient, gender of the perpetrator, age of the perpetrator, marital status of the perpetrator and the marital status of the recipient, were synthesised into the broader theme 'perceived appropriateness or the perceived motive of the perpetrator' as all five of these initial codes indicated how a recipient would perceive the appropriateness of the motive of the perpetrator based on these codes / factors, which ultimately lead to the interpretation of the sexual conduct. .

Step 8: The framework was developed considering the broader themes and the codes and their relationship with the interpretation of sexual conduct.

\section{Framework: How Do Women Interpret Sexual Harassment at the Workplace?}

Drawing from the literature, it is proposed that when a conduct of a sexual nature (social-sexual behaviour) is experienced by a woman at the workplace, whether it is harassing or not for her will depend on: a) perceived appropriateness or the perceived motive of the perpetrator, b) personal vulnerability of the recipient, c) personal sensitivity of the recipient to sexual harassment, d) experiential attributes, and e) the context and culture in which the experience occurs. As shown in Figure 1, these aspects overlap, creating complicated intersections, where they independently or together affect the interpretation in an interactive process.

\section{Perceived Appropriateness or the Perceived Motive of the Perpetrator}

It is said that when a recipient perceives ulterior sexual interests / motives of a perpetrator or when the perpetrator's behaviour is seen as inappropriate, there is a greater tendency for the recipient to interpret that behaviour as harassing (Lindgren, Parkhill, George, \& Hendershot, 2008; Marks \& Nelson, 1993; Wiener \& Hurt, 1997). Lindgren et al. (2008) discuss this as 'sexual intent assessment' or 'sexual intent perception' and define it as "the assessment of one person's interest in pursuing 
Figure 1: How Sexual Harassment is Interpreted by Women at the Workplace

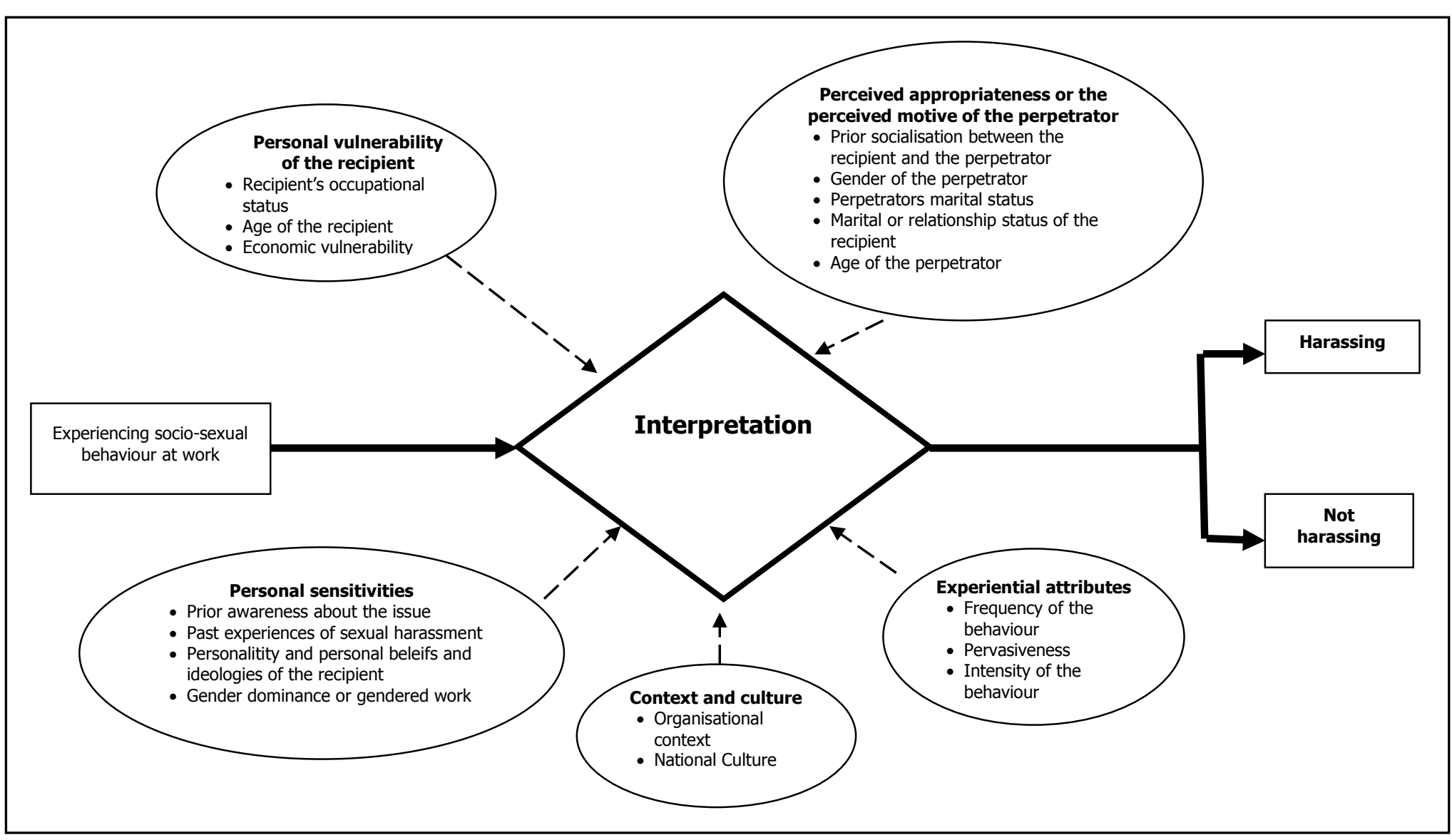


sexual activity" (p. 424). While only a few studies have directly explored this concept, there are many other studies that have identified various factors that can influence the recipients' judgment of appropriateness of a behaviour, as discussed below.

\section{Prior Socialisation between the Recipient and the Perpetrator}

Research has consistently shown how a sexual conduct is interpreted by the recipient based on the prior socialisation between the parties (Cogin \& Fish, 2007; Dougherty et al., 1996; Hurt et al., 1999). As Dougherty et al. (1996) report

prior relationships between the parties influence role expectations and therefore may influence perceptions of harassment because the meaning and evaluation of behaviours are different for those in prior relationships. A woman, for example, may be less offended by verbal comments or even touching by a male she has socialised with, because her perception of the meaning of the behaviour suggests that such behaviours are appropriate. (p. 491)

Accordingly, when the perpetrator of a sexual conduct is known to the recipient or when the recipient has socialised with the person before, the recipient is less likely to see certain sexual conduct as harassing or intimidating, or to suspect any ulterior or sexual motives. On the contrary, when the behaviour is perpetrated by a person not known to the recipient, his behaviour can be seen as harassing, inappropriate or carrying underlying sexual connotations.

\section{Gender of the Perpetrator}

Prior research also points towards the gender of the perpetrator in interpreting inappropriateness, where it is said that women are less tolerant of sexual conducts and tend to perceive them as more harassing when the perpetrator is a male rather than a female (Hendrix, 2000; Jones \& Remland, 1992; Marks \& Nelson, 1993; McCabe \& Hardman, 2005). This can be linked to the gender role stereotyping beliefs in societies, where men's sexuality is promoted and regarded as an inherent tendency, and where initiation of sexual relationships is regarded as a role of men (Luther \& Luther, 2002). Hence, there is a higher propensity for a woman to perceive certain behaviours and communications initiated by a man as an intention to instigate sexual intimacy / relationship or sexual interest, as against an act of a heterosexual woman.

\section{Perpetrator's Marital Status}

Researchers also highlight (Marks \& Nelson, 1993; Pryor, 1995) how a perpetrator's marital status would affect a recipient's interpretation of a sexual conduct. It is said that a married person's behaviours are seen as more harassing than 
those of an unmarried person, as there is a normative expectation of appropriate behaviour from a married person (Pryor \& Day, 1988). In contrast, an unmarried person's behaviour can be seen to have a genuine interest or innocent flirtation and thus as not inappropriate or harassing.

\section{Marital or Relationship Status of the Recipient}

While marital status is discussed in prior research more in relation to women's vulnerability to sexual harassment (O'Donohue, Downs, Yeater, 1998), it is also found to affect how recipients' interpret sexual conduct / harassment (Giuffre \& Williams, 1994; Hendrix, 2000; Nielsen, 1996; Pickerill et al., 2006). Being married is seen as a shield against sexual harassment by some women and is used to negotiate their interactions with men at work to avoid being subjected to unwanted sexual interests of men (Giuffre \& Williams, 1994). Notwithstanding these efforts, when they are being subjected to sexual conduct, married women perceive them as more inappropriate.

\section{Age of the Perpetrator}

Even though studies exploring the age of a perpetrator as a factor affecting the interpretation of a sexual conduct by a recipient are sparse, the existing studies (Hendrix, 2000; Pryor, LaVite, \& Stoller, 1993; Schultz, 1998) indicate that women tend to identify sexual conduct by older men as more harassing than sexual conduct by younger men. This too can be linked to the perception of appropriateness, where women perceive an older man's behaviour as more inappropriate or as encompassing ulterior motives than that of a younger person.

\section{Personal Vulnerability of the Recipient}

Certain characteristics of women such as age, gender, marital status, or occupational position can make them more susceptible or vulnerable to sexual harassment (Kohlman, 2004; O'Connell \& Korabik, 2000). This concept of personal vulnerability (O'Connell \& Korabik, 2000) can also be linked to how social-sexual behaviour is interpreted by a woman. A woman can be found to feel more vulnerable and thus more harassed by experiencing certain social-sexual behaviour due to various reasons as discussed below.

\section{Recipient's Occupational Status}

$A$ woman can feel vulnerable in relation to her occupational status in two ways. On one hand, her lower occupational status per se can make a woman more vulnerable 
(due to lack of power) and sensitive to sexual harassment (Fitzgerald et al., 1997; Maeder et al., 2007; Reese \& Lindenberge, 2005), affecting her interpretation of sexual conduct at work. It is said that women occupying higher occupational status might interpret a behaviour as less harassing owing to their organisational power (Fitzgerald et al., 1997). On the other hand, a woman's occupational status vis a vis a perpetrator can also make a woman feel vulnerable as the hierarchical power of a perpetrator would demand obedience (Dougherty et al., 1996) and indicate more negative outcomes for refusal (O'Connell \& Korabik, 2000). Hence, behaviours perpetrated by superiors are generally perceived as more frightening (Settles, Buchanan, Yap, \& Harrell,, 2014), harassing or serious than the same behaviour perpetrated by a peer (Bluemental, 1998; Charlesworth, McDonald, \& Cerise, 2011; Dougherty et al., 1996; Gordon et al., 2005; McDonald, 2012; Rotundo et al., 2001).

\section{Age of the Recipient}

Even though there are contradicting findings (McCabe \& Hardman, 2005), Foulis and McCabe (1997) report how the "acceptance of sexually harassing behaviour decreases as age increases or, alternatively, that increase in exposure to the workforce is associated with less acceptance of such behviour" (p. 786). It is thus said that older females are more likely to be aware of and sensitive to sexual harassment with their longer work experience and socialisation in a work environment and hence interpret more behaviours as such, whereas younger women would tolerate and accept more sexually harassing behaviours (Blackstone, Houle, \& Uggen, 2014; Foulis \& McCabe; Ohse \& Stockdale, 2008; Reese \& Lindenberge, 2005).

\section{Economic Vulnerability of the Recipient}

Economic vulnerability is another factor that impacts women's interpretation of sexual conduct. While prior research mainly discuss economic vulnerability in relation to the risk of being harassed (Cortina, Swan, Fitzgerald, \& Waldo, 1998; Fitzgerald, 1993; Shupe, Cortina, Ramos, Fitzgerald, \& Salisbury, 2002) or in relation to women's coping strategies (Wasti \& Cortina, 2002), it can also reduce a woman's ability to dictate or control the situation and fear a loss of income, making them feel more intimidated or harassed.

\section{Personal Sensitivities}

A recipient's sensitivity about the issue of sexual harassment too can influence her interpretation of social-sexual behaviour at work (Hinze, 2004). A recipient can become more or less sensitive to the issue through various means as discussed below. 


\section{Prior Awareness of the Issue}

Awareness of sexual harassment has been discussed extensively in past literature in relation to perception and interpretation. As research indicates, when people are aware of the issue, more behaviours would be considered as sexual harassment than when they are unaware of the issue (Brewis, 2001; Jaschik-Herman \& Fisk, 1995; Pickerill et al., 2006). As such, awareness makes it easier for women to identify sexual harassment (Antecol \& Cobb-Clark, 2003). There are numerous ways in which awareness, and through it, sensitivity, is gained by recipients. Receiving training on sexual harassment (Buckner, Hindman, Huelsman, \& Bergman, 2014), knowing victims of sexual harassment personally or through the media (Wiener, Voss, Winter, \& Arnot, 2005), being exposed to the publicity given (Jaschik-Herman \& Fisk, 1995; Pickerill et al., 2006), gaining legal knowledge (Tinkler, 2008), legal consciousness (Nielsen, 2000), and organizational policies (Antecol \& Cobb-Clark, 2003) are thus found to heighten people's awareness and sensitivity about the issue, affecting their interpretation of sexual harassment.

\section{Past Experiences of Sexual Harassment}

Previous victimisation (Wright \& Fitzgerald, 2007; Stockdale et al., 2014) too would heighten women's sensitivity about the issue where they would identify more behaviours as sexual harassment (Dougherty et al., 1996; Gowan \& Zimmerman, 1996; McCabe \& Hardman, 2005) and vice versa. There are also conflicting viewpoints about women with past experiences being more tolerant of sexually harassing behaviours (Foulis \& McCabe, 1997). All in all, with more sensitivity due to previous experiences of sexual harassment, women can either be more tolerant or less tolerant towards sexual conduct / harassment.

\section{Personality and Personal Beliefs and Ideologies of the Recipient}

There are only very few studies that have directly explored the relationship between personality types and sexual harassment sensitivity (Crow et al., 1995). Yet, different facets of the personality such as self-esteem (Crow et al., 1995; Malovich \& Stake, 1990), attitudes (Foulis \& McCabe, 1997) and self-identification as a feminist and engagement in women's rights activism (Holland \& Cortina, 2013) can be identified as affecting sexual harassment sensitivity. Women with higher self-esteem (Crow et al., 1995; Malovich \& Stake, 1990) and those who are more self-assured, unworried and complacent are said to be less bothered by certain sexual conducts (Wear, Aultman, \& Borges, 2007). Wear et al. (2007) call these individuals more "thick-skinned" rather than "threat-sensitive". At the same time, women with feminist attitudes are found to be less tolerant of sexual conduct at work (Foulis \& McCabe, 
1997; Holland \& Cortina, 2013) and hence might interpret a broader set of sexual conducts at work as harassing.

The ideological position (Scarduzio \& Geist-Martin, 2010), beliefs and values (Tinkler, 2008) and moral reasoning (Bernstein, 1997), gender role stereotyping attitudes (Adikaram, 2014; Dill, Brown, \& Collins, 2008; Foulis \& McCabe, 1997) too are found to shape how people make sense of experiences of sexual harassment. Further, women who are low on hostile sexism (Wiener \& Hurt, 2000), women with adversarial sexual beliefs (Murrell \& Dietz-Uhler, 1993), and non-sexist attitudes (Foulis \& McCabe, 1997; Lee, 2001) are also found to be less likely to identify a behaviour as harassing. Further, women high on masculinity were found to perceive more behaviours as sexual harassment than women low on masculinity (Foulis \& McCabe, 1997; McCabe \& Hardman, 2005). On the whole, these different personalities as well as personal beliefs and ideologies either increase or decrease sexual harassment sensitivity and, in turn, affects how a woman would interpret her experiences of social-sexual conduct at work.

\section{Gender Dominance or Gendered Work}

Gender dominance or gendered work is discussed at length by prior researchers, who say that women in traditionally male occupations or where men dominate workplaces numerically or normatively, experience more sexual harassment than other women (Cogin \& Fish, 2007; McLaughlin, Uggen, \& Blackstone, 2012; Welsh, 1999). This male dominance, while heightening the experiences of sexual harassment, will also make women feel vulnerable as a minority, making them more sensitive to sexual conducts of men, and thus impacting their interpretation of sexual harassment. As Ellis, Barak, and Pinto, (1991) state, "the feeling of belonging to the women's minority group tends to influence women's subjective perceptions of being sexually harassed" (p. 1332).

\section{Experiential Attributes}

Different attributes of the harassing experience itself will also affect the interpretation of sexual conducts at the workplace as follows:

\section{Frequency of the Behaviour}

How the frequency of a social-sexual behaviour can affect the interpretation or appraisal of that behaviour is explored in various prior studies (Bernstein, 1997; Hinze, 2004; Hitlan et al., 2006; Langhout, et al., 2005). Studies generally indicate that when a behaviour is frequent, there is a greater possibility of it being interpreted 
as upsetting or harassing (Hitlan et al., 2006) whereas, if the behaviour is not frequent, it can be interpreted as a rarity (Langhout et al., 2005). On the contrary, Stockdale et al. (1995) indicate that such a relationship does not exist and that when a behaviour is frequent it can be seen as normal and hence not interpreted as sexual harassment. Hence, due to its commonality or rarity, a behaviour can be either seen as more harassing or not harassing by a recipient.

\section{Pervasiveness}

According to Denissen (2010), a recipient may first attempt to overlook sexual conduct directed at her, but if the behaviour continues after initial attempts to resolve the issue or if the behaviour is considered extreme, it may be reinterpreted as "crossing the line". It is said that if a perpetrator discontinues a behaviour at the request of the recipient, it is interpreted that the perpetrator did not intend harm (Osman, 2007), whereas if a behaviour continues even after resistance, it confirms the harassment for the recipient (Osman, 2007; Marshall, 2003). Hence, pervasiveness or continuation of the behaviour despite resistance also emerge as a factor contributing to the interpretation of a social-sexual behaviour (Denissen, 2010, Knapp, Faley, Ekeberg, \& Dubois, 1997; Langhout et al., 2005; Osman 2007; Wasti \& Cortina 2002; Wiener \& Hurt, 1997; Yoder \& Aniakudo, 1995).

\section{Intensity of the Behaviour}

Intensity is one of the most studied factors in sexual harassment research (Barr, 1993; Denissen, 2010; Marshall, 2003; Ng \& Othman, 2002; Osman, 2007) and generally means the magnitude or severity of the harassing behaviours (Wright \& Fitzgerald, 2007). It is documented that people tend to interpret more severe behaviours such as assault, touching, and sexual propositions as sexual harassment more definitely, than less severe behaviours such as leering, joking, sexual comments and showing sexually explicit pictures (Osman, 2007). Sometimes the intensity is linked to the physical or non-physical nature of a behaviour (Charlesworth et al., 2011), where physical behviours are seen as more harassing compared to nonphysical behaviours (Osman, 2007; Salisbury \& Dominick, 2004). For example, verbal harassment may appear to be less threatening and more socially acceptable than harassment involving physical contact (Dougherty et al., 1996; McDonald, 2012; Salisbury \& Dominick, 2004).

\section{Context and Culture}

Context and culture within which sexual conduct / harassment occurs and its impact on different aspects of sexual harassment such as prevalence (Timmerman \& 


\section{Adikaram}

Bajema, 1999), and coping (Cortina \& Wasti, 2005), have been studied considerably. How context and culture can affect the interpretation of a behaviour has also been highlighted in prior research as follows.

\section{Organisational Context}

Organisational context has been widely studied in sexual harassment research, mainly as an antecedent (Chamberlain, Crowley, Tope, \& Hodson, 2008; O'Connell \& Korabik, 2000; Timmerman \& Bajema, 2000; Vogt et al., 2007) and also as a factor affecting the subjective appraisal and outcomes of social-sexual behaviour at work (Fitzgerald et al., 1997). As literature indicates, work cultures known as 'sexualised' (where sexual conducts such as sexual jokes, comments, innuendoes, and sexual or seductive dress is tolerated, condoned, and encouraged) (Gutek et al., 1990) lead to the institutionalisation of hegemonic norms of acceptable sexual conducts affecting how women interpret these conducts (Dellinger \& Williams, 2002; Firestone \& Harris 2003; Giuffre \& Williams 1994; Kensbock, Bailey, Jennings, \& Patiar, 2015; O'Connor et al., 2004). According to Handy (2006), different organisational settings are said to have their own norms about acceptable and unacceptable sexual conducts and these norms will become shared understandings and interpretations of sexual harassment. "While these shared understandings are normalised and implicitly legitimised forms of harassment, they also help women cope by supplying informal guidelines for interpreting different behaviours" (Handy, 2006, p. 20). Therefore, women in organisational settings where sexual conducts are common and sexuality is used and accepted as part of work, would interpret their experiences more broadly and thus as not harassing (Brunner \& Dever, 2014) and vise versa.

\section{National Culture}

As prior research document, which behaviours are harassing depends on different cultures (Limpaphayom, Bailey, Jennings, \& Patiar, 2006) based on different ethics, values, and norms. It is commonly identified that behaviour that is considered appropriate in one culture might not be seen as appropriate in another culture (Bernstein, 1997; Gee \& Norton, 1999; Limpaphayom et al., 2006; Marshall, 2003; Ng \& Othman, 2002; Pryor et al., 1997; Timmerman \& Bajema, 1999; Zimbroff, 2007). For example, Gelfand, Fitzgerald and Drasgow (1995) found how Brazilians, unlike North Americans, did not perceive sexual harassment as an abuse of power or gender discrimination. Brazilians are also found to view sexual advances as less harmful and more as innocent romantic moves (Desouza, Pryor, \& Hutz, 1998). This difference in interpretation is due to cultural factors such as gender role (Barr, 1993; 
Foulis \& McCabe, 1997), religion, political ideology, history, beliefs about women, tradition, customs, laws (Gee \& Norton, 1999) as well as gender ideologies, social and cultural norms (Desouza et al., 1998). The impact of various cultural dimensions identified by Hofstede (Luthar \& Luthar, 2002; Whaley \& Tucker, 1998) has also been discussed in relation to the interpretation of sexual harassment. All in all, it can be said that culture of a country too has an influence on the manner in which a socialsexual behaviour is construed by a recipient.

\section{Conclusion}

Being very subjective and personal, interpretation of sexual harassment has undoubtedly been identified as a very complex and ambiguous matter. What is sexual harassment to one person, may not be so to another. Certain social-sexual behaviours at the workplace will be welcomed and enjoyed by some women, tolerated and accepted by some others, and considered as sexual harassment by some. Within this background, an understanding was sought on how and in what contexts women interpret their experiences of sexual conduct at work as sexual harassment. Accordingly, the present review proposes that when social-sexual behaviour is experienced by a woman at the workplace, whether it is harassing or not for her will depend on: a) the perceived appropriateness or the perceived intentions of the harasser (based on factors such as prior socialisation between the recipient and the perpetrator, gender of the perpetrator, perpetrator's marital status, marital or relationship status of the recipient and age of the perpetrator), b) personal vulnerability of the recipient (based on the recipient's occupational status, her age and her economic vulnerability), c) personal sensitivities of the recipient (based on prior awareness of the issue, past experiences of sexual harassment, personality and personal beliefs and ideologies of the recipient, and gender dominance or gendered work in the workplace), d) experiential attributes (based on the frequency of the behaviour, pervasiveness and intensity of the behaviour) and e) the context within which the situation occurred (based on the organisational context and the national culture). These aspects and the associated factors therein will confluence and intertwine with each other indicating the complex nature of the interpretation of sexual harassment.

\section{Declaration of Conflicting Interests}

The authors declared no potential conflicts of interest with respect to the research, authorship, and publication of this article. 


\section{References}

Adikaram, A. S. (2014). Good women and bad women: How socialization of gendered behavioural norms influences Sri Lankan working women's interpretation of sexual harassment at workplaces. South Asian Journal of Human Resources Management, 1(1), 45-65. doi: 10.1177/2322093714526662

Aquino, K., Sheppard, L., Watkins, M. B., O’Reilly, J., \& Smith, A. (2014). Social sexual behaviour at work. Research in Organizational Behaviour, 34, 217-236. doi: 10.1016/j.riob.2014.02.001

Antecol, H., \& Cobb-Clark, D. (2003). Does sexual harassment training change attitudes? A view from the federal level. Social Science Quarterly, 84(4), 826842. doi: 10.1046/j.0038-4941.2003.08404001.x

Barr, P. A. (1993). Perceptions of sexual harassment. Sociological Inquiry, 63(4), 460-471. 10.1111/j.1475-682X.1993.tb00325.x

Berdahl, J. L., \& Aquino, K. (2009). Sexual behaviour at work: Fun or folly? Journal of Applied Psychology, 94(1), 34-47. doi: 10.1037/a0012981

Bernstein, A. (1997). Treating sexual harassment with respect. Harvard Law Review, 111(2), 445-527. doi: 10.2307/1342057

Bingham, S. G. (Ed.). (1994). Conceptualizing sexual harassment as discursive practice. Praeger Publishers.

Blackstone, A., Houle, J., \& Uggen, C. (2014). I didn't recognize it as a bad experience until I was much older: Age, experience and workers perceptions of sexual harassment. Sociological Spectrum, 34(4), 314-337. doi: 10.1080/02732173.2014.917247

Blanchette, I., \& Richards, A. (2010). The influence of affect on higher level cognition: A review of research on interpretation, judgment, decision making and reasoning. Cognition and Emotion, 24(4), 561-595. doi: 10.1080/02699930903132496

Blumenthal, J. A. (1998). The reasonable woman standard: A meta-analytic review of gender differences in perceptions of sexual harassment. Law and Human Behavior, 22(1), 33-57.

Braun, V. \& Clarke, V. (2006). Using thematic analysis in psychology. Qualitative Research in Psychology 3 (2), 77-101. doi:10.1191/1478088706qp063oa.

Brewis, J. (2001). Foucault, politics and organizations: (Re)-constructing sexual harassment. Gender, Work and Organization, 8(1), 37-60. doi: 10.1111/14680432.00121

Brunner, L. K., \& Dever, M. (2014). Work, bodies and boundaries: Talking sexual harassment in the new economy. Gender, Work and Organization, 21(5), 459471. doi: $10.1111 / \mathrm{gwao} .12048$ 
Buckner, G. E., Hindman, H. D., Huelsman, T. J., \& Bergman, J. Z. (2014). Managing workplace sexual harassment: The role of manager training. Employee Responsibilities and Rights Journal, 26(4), 257-278. doi: 10.1007/s10672-0149248-z

Chamberlain, L. J., Crowley, M., Tope, D., \& Hodson, R. (2008). Sexual harassment in organizational context. Work and Occupations, 35(3), 262-295. doi: $10.1177 / 0730888408322008$

Charlesworth, S., McDonald, P. \& Cerise, S. (2011). Naming and claiming workplace sexual harassment in Australia. Australian Journal of Social Issues, 46(2), 141161. doi: 10.1002/j.1839-4655.2011.tb00211.x

Cogin, J., \& Fish, A. (2007). Managing sexual harassment more strategically: An analysis of environmental causes. Asia Pacific Journal of Human Resources, 45(3), 333-352. doi 10.1177/1038411107082277.

Cortina, L. M., \& Berdahl, J. L. (2008). Sexual harassment in organizations: A decade of research in review. In J. Barling \& C. L. Cooper (Eds.), The Sage Handbook of organizational behaviour Vol. 1 (pp. 469-497). Los Angeles, London, New Delhi, Singapore: Sage.

Cortina, L. M., Swan, S., Fitzgerald, L. F., \& Waldo, C. (1998). Sexual harassment and assault: Chilling the climate for women in academia Psychology of Women Quarterly, 22(3), 419-441. doi: 10.1111/j.1471-6402.1998.tb00166.x

Cortina, L. M., \& Wasti, S. A. (2005). Profiles in coping: Responses to sexual harassment across persons, organizations, and cultures. Journal of Applied Psychology, 90(1), 182-192. doi: 10.1037/0021-9010.90.1.182

Crow, S. M., Hartman, S. J., Hammond, D., \& Fork, L. Y. (1995). The impact of personality factors on sexual and non-sexual harassment sensitivity. Women in Management Review, 10(6), 9-19. doi: 10.1108/09649429510095980

Dellinger, K., \& Williams, C. L. (2002). The locker room and the dorm room: Workplace norms and the boundaries of sexual harassment in magazine editing. Social Problems, 49(2), 242-257. doi: 10.1525/sp.2002.49.2.242

Denissen, A. M. (2010). Crossing the line: How women in the building trades interpret and respond to sexual conduct at work. Journal of Contemporary Ethnography, 39(3), 297-327. doi: 10.1177/0891241609341827

De Souza, E. R., Pryor, J. B., \& Hutz, C. S. (1998). Reactions to sexual harassment charges between North Americans and Brazilians. Sex Roles, 39(11-12), 913928. doi:10.1023/A:1018884807080

Dill, K. E., Brown, B. P., \& Collins, M. A. (2008). Effects of exposure to sexstereotyped video game characters on tolerance of sexual harassment. Journal of Experimental Social Psychology, 44(5), 1402-1408. doi: 10.1016/j.jesp.2008.06.002 
Dougherty, D., \& Smythe, M. J. (2004). Sensemaking, organizational culture, and sexual harassment. Journal of Applied Communication Research, 32(4), 293317. doi: $10.1080 / 0090988042000275998$

Dougherty, T. W., Turban, D. B., Olson, D. E., Dwyer, P. D., \& Lapreze, M. W. (1996). Factors affecting perceptions of workplace sexual harassment. Journal of Organizational Behaviour, 17(5), 489-501. doi: 10.1002/(SICI)10991379(199609)17:5<489::AID-JOB780>3.0.CO;2-6

Ellis, S., Barak, A., \& Pinto, A. (1991). Moderating effects of personal cognitions on experienced and perceived sexual harassment of women at the workplace. Journal of Applied Social Psychology, 21(16), 1320-1337. doi: 10.1111/j.15591816.1991.tb00473.x

Equal Employment Opportunity Commission Guidelines on Discrimination Because of Sex, 29 CFR § 1604.11 (1980 as amended in 1999).

Firestone, J. M., \& Harris, R. J. (2003). Perceptions of effectiveness of responses to sexual harassment in the US military, 1988 and 1995. Gender, Work and Organization, 10(1), 42-64. doi: 10.1111/1468-0432.00003

Fitzgerald, L. F. (1993). Sexual harassment: Violence against women in the workplace. American Psychologist, 48(10), 1070-1076. doi: 10.1037/0003066X.48.10.1070

Fitzgerald, L. F., Swan, S. \& Magley, V. J. (1997). But was it really sexual harassment? Legal, behvioural and psychological definitions of the workplace victimization of women. In E. O'Donohue (Ed.), Sexual harassment: Theory, research and treatment (pp. 5-28). Boston, London, Toronto: Allyn and Bacon.

Foulis, D., \& McCabe, M. P. (1997). Sexual harassment; Factors affecting attitudes and perceptions. Sex Roles, 37(9/10), 773-798. doi:10.1007/BF02936339

Gee, M. V., \& Norton, S. M. (1999). The confluence of gender and culture: Sexual harassment in the international arena. Management Decision, 37(5), 417-423. doi: 10.1108/00251749910274199

Gelfand, M. J., Fitzgerald, L. F. \& Drasgow, F. (1995). The structure of sexual harassment: A confirmatory analysis across cultures and settings. Journal of Vocational Behaviour, 47(2), 164-177. doi: 10.1006/jvbe.1995.1033

Giuffre, P. A., \& Williams, C. L. (1994). Boundary lines: Labeling sexual harassment in restaurants. Gender and Society, 8(3), 378-401. doi: 10.1177/ 089124394008003006

Gordon, A. K., Cohen, M. A., Grauer, E. \& Rogelberg, S. (2005). Innocent flirting or sexual harassment? Perceptions of ambiguous work-place situations. Representative Research in Social Psychology, 28, 47-58.

Gowan, M. A. \& Zimmermann, R. A. (1996). Impact of ethnicity, gender, and previous experience on juror judgments in sexual harassment cases. Journal of 
Applied Social Psychology, 26(7), 596-617. doi: 10.1111/j.15591816.1996.tb02733.x

Gutek, B. A., \& O'Conner, M. (1995). The empirical basis for the reasonable woman standard. Journal of Social Issues, 51(1), 151-166. doi: 10.1111/j.15404560.1995.tb01314.x

Gutek, B. A., Cohen, A. G., \& Konrad, A. M. (1990). Predicting social-sexual behaviour at work: A contact hypothesis. Academy of Management Journal, 33(3), 560-577. doi: 10.5465/256581

Handy, J. (2006). Sexual harassment in small-town New Zealand: A qualitative study of three contrasting organizations. Gender, Work and Organization, 13(1), 1-24. doi: 10.1111/j.1468-0432.2006.00293.x

Hendrix, W. H. (2000). Perceptions of sexual harassment by student-employee classification, marital status, and female racial classification. Journal of Social Behaviour and Personality, 15(4), 529-544.

Hinze, S. W. (2004). Am I being over-sensitive? Women's experience of sexual harassment during medical training. Health: An Interdisciplinary Journal for the Study of Health, Illness and Medicine, 8(1), 101-127. doi: 10.1177/ 1363459304038799

Hitlan, R. T., Schneider, K. T., \& Walsh, B. M. (2006). Upsetting behaviour: Reactions to personal and bystander sexual harassment experinces. Sex Roles, 55, 187-195. doi: 10.1007/s11199-006-9072-5

Holland, K. J., \& Cortina, L. M. (2013). When sexism and feminism collide: The sexual harassment of feminist working women. Psychology of Women Quarterly, 37(2), 192-208. doi: 10.1177/0361684313482873

Hunt, C. M., Davidson, M. J., Fielden, S. L., \& Hoel, H. (2010). Reviewing sexual harassment in the workplace-an intervention model. Personnel Review, 39(5), 655-673. doi: 10.1108/00483481011064190

Hurt, L. E., Wiener, R. L., Russell, B. L., \& Mannen, R. K. (1999). Gender differences in evaluating social-sexual conduct in the workplace. Behavioural Sciences and the Law, 17, 413-433. doi: 10.1002/(SICI)1099-0798(199910/12)17:4< 413::AID-BSL364>3.0.CO;2-B

Jaschik-Herman, M. L., \& Fisk, A. (1995). Women's perceptions and labeling of sexual harassment in academia before and after the Hill-Thomas hearings. Sex Roles, 33(5-6), 439-446. doi: 10.1007/BF01954578

Jones, T. S., \& Remland, M. S. (1992). Sources of variability in perceptions of and responses to sexual harassment. Sex Roles, 27(3-4), 121-142. doi: 10.1007/BF00290013 
Kensbock, S., Bailey, J., Jennings, G., \& Patiar, A. (2015). Sexual harassment of women working as room attendants within 5-star hotels. Gender, Work and Organization, 22(1), 36-50. doi: 10.1111/gwao.12064

Knapp, D. E., Faley, R. H., Ekeberg, S. E., \& Dubois, C. L. (1997). Determinants of target responses to sexual harassment: A conceptual framework. Academy of Management Review, 22(3), 687-729. doi: 10.5465/amr.1997.9708210723

Kohlman, M. H. (2004). Person or position?: The demographics of sexual harassment in the workplace. Equal Opportunities International, 23(3/4/5), 143-161. doi: $10.1108 / 02610150410787774$

Langhout, R. D., Bergman, M. E., Cortina, L. M., Fitzgerald, L. F., Drasgow, F., \& Williams, J. H. (2005). Sexual harassment severity: Assessing situational and personal determinants and outcomes. Journal of Applied Social Psychology, 35(5), 975-1007. doi: 10.1111/j.1559-1816.2005.tb02156.x

Lee, D. (2001). He didn't sexually harass me, as in harassed for sex... he was just horrible: Women's definitions of unwanted male sexual conduct at work. Women's Studies International Forum, 24(1), 25-38. 10.1016/S02775395(00)00163-1

Limpaphayom, W., Williams, R. J., \& Fadil, P. A. (2006). Perceived differences in sexual harassment between business school students in the US and Thailand. Cross Cultural Management: An International Journal, 13(1), 32-42. doi: 10.1108/13527600610643466

Lindgren, K. P., Parkhill, M. R., George, W. H., \& Hendershot, C. S. (2008). Gender differences in pereptions on sexual intent: A qualitative review and integration. Psychology of Women Quarterly, 32, 423-439. doi: 10.1111/j.14716402.2008.00456.x

Lonsway, K. A., Paynich, R., \& Hall, J. N. (2013). Sexual harassment in law enforcement: Incidence, impact and perception. Police Quarterly, 16(2), 177210. doi: 10.1177/1098611113475630

Luthar, V. K., \& Luthar, H. K. (2002). Using Hofstede's cultural dimensions to explain sexually harassing behaviours in an international context. International Journal of Human Resource Management,13(2), 268-284. doi: 10.1080/09585190110102378

Maeder, E. M., Wiener, R. L., \& Winter, R. (2007). Does a truck driver see what a nurse sees? The effects of occupation type on perceptions of sexual harassment. Sex Roles, 56(11-12), 801-810. doi:10.1007/s11199-007-9244-y

Malovich, N. J., \& Stake, J. E. (1990). Sexual harassment on campus: Individual differences in attitudes and beliefs. Psychology of Women Quarterly, 14(1), 6381. doi: 10.1111/j.1471-6402.1990.tb00005.x 
Marks, M. A., \& Nelson, E. S. (1993). Sexual harassment on campus: Effects of professor gender on perception of sexually harassing behaviours. Sex Roles, 28(34), 207-217. doi:10.1007/BF00299281

Marshall, A. M. (2003). Injustice frames, legality, and the everyday construction of sexual harassment. Law \& Social Inquiry, 28(3), 659-689. doi: 10.1111/j.17474469.2003.tb00211.x

McCabe, M. P., \& Hardman, L. (2005). Attitudes and perceptions of workers to sexual harassment. The Journal of Social Psychology, 145(6), 719-740. doi: 10.3200/SOCP.145.6.719-740

McDonald, P. (2012). Workplace sexual harassment 30 years on: A review of the literature. International Journal of Managament Review, 14, 1-17. doi: 10.1111/j.1468-2370.2011.00300.x

McLaughlin, H., Uggen, C., \& Blackstone, A. (2012). Sexual harassment, workplace authority, and the paradox of power. American Sociological Review,77(4), 625647. doi: 10.1177/0003122412451728

Murrell, A. J., \& Dietz-Uhler, B. L. (1993). Gender identity and adversarial sexual beliefs as predictors of attitudes towards sexual harassment. Psychology of Women Quarterly, 17, 169-175. doi: 10.1111/j.1471-6402.1993.tb00442.x

$\mathrm{Ng}, \mathrm{C}$., \& Othman, J. (2002). Unwanted and unwelcome: Sexual harassment in the Malaysian workplaces. Gender Technology and Development, 6(3), 389-407. doi: 10.1080/09718524.2002.11910056

Nielsen, L. B. (2000). Situating legal consciousness: Experiences and attitudes of ordinary citizens about law and street harassment. Law \& Society Review, 34(4), 1055-1090. doi:10.2307/3115131

Nielsen, W. R. (1996). Perceptions of sexual harassment: A female office professional's perspective. Employee Counselling Today,8(4), 6-14. doi: 10.1108/13665629610121614

O'Connell, C. E., \& Korabik, K. (2000). Sexual harassment: The relationship of personal vulnerability, work context, perpetrator status, and type of harassment to outcomes. Journal of Vocational Behaviour, 56, 299-329. doi: 10.1006/ jvbe.1999.1717

O'Connor, M., Gutek, B. A., Stockdale, M., Geer, T. M., \& Melancon, R. J. (2004). Explaining sexual harassment judgements: Looking beyond gender of the rater. Law and Human Behaviour, 28(1), 69-95. doi: 10.1023/B:LAHU. 0000015004.39462.6e

O’Donohue, W., Downs, K., \& Yeater, E. A. (1998). Sexual harassment: A review of the literature. Aggression and Violent Behaviour, 3(2), 111-128. doi: 10.1016/ S1359-1789(97)00011-6 
Ohse, D. M., \& Stockdale, M. S. (2008). Age comparisons in workplace sexual harassment perceptions. Sex Roles, 59(3-4), 240-253. doi:10.1007/s11199-0089438-y

Osman, S. L. (2007). The continuation of perpetrator behaviour that influence perceptions of sexual harassment. Sex Roles, 56, 63-69. doi: 10.1007/s11199006-9149-1

Page, T. E., Pina, A., \& Giner-Sorolla, R. (2015). It was only harmless banter! The development and preliminary validation of the moral disengagement in sexual harassment scale. Aggresive Behaviour, 86(5), 1-20. doi: 10.1002/ab.21621

Pickerill, J. M., Jackson, R. A., \& Newman, M. A. (2006). Changing perceptions of sexual harassment in the federal workforce, 1987-94. Law and Policy, 28(3), 368-394. doi: 10.1111/j.1467-9930.2006.00231.x

Pryor, J. B. (1995). The psychological impact of sexual harassment on women in the US military. Basic and Applied Social Psychology, 17(4), 581-603. doi: 10.1207/s15324834basp1704_9

Pryor, J. B., \& Day, J. D. (1988). Interpretations of sexual harassment: An attributional analysis. Sex Roles, 18(7-8), 405-417. doi: 10.1007/BF00288392

Pryor, J. B., LaVite, C. M., \& Stoller, L. M. (1993). A social psychological analysis of sexual harassment: The person/situation interaction. Journal of Vocational Behaviour, 42(1), 68-83. doi: 10.1006/jvbe.1993.1005

Reese, L. A., \& Lindenberg, K. E. (2005). Gender, age, and sexual harassment. Review of Public Personnel Administration, 25(4), 325-352. doi: 10.1177/0734371X04272349

Rotundo, M., Nguyen, D. H., \& Sackett, P. R. (2001). A meta-analytic review of gender differences in perceptions of sexual harassment. Journal of Applied Psychology, 86(5), 914-922. doi: 10.1037/0021-9010.86.5.914

Salisbury, J. C., \& Dominick, D. K. (2004). Investigating harassment and discrimination complaints: A practical guide. San Francisco: John Wiley/Pfeiffer.

Scarduzio, J. A., \& Geist-Martin, P. (2010). Accounting for victimization: Male professors' ideological positioning in stories of sexual harassment. Management Communication Quarterly, 24(3), 419-445. doi: 10.1177/0893318909358746

Schultz, V. (1998). Reconceptualizing sexual harassment. The Yale Law Journal, 107(6), 1683-1805.

Settles, I. H., Buchanan, N. T., Yap, S. Y., \& Harrell, Z. A. (2014). Sex difference in outcomes and harasser charachteristics associated with firghtening sexual harassment appraisals. Journal of Occupational Health Psychology, 19(2), 133142. doi: 10.1037/a0035449 
Settles, I. H., Harrell, Z. A., Buchanan, N. T., \& Yap, S. C. (2011). Frightened or bothered: Two types of sexual harassment appraisals. Social Psychological and Personality Science, 2(6), 600-608. doi: 10.1177/1948550611402520

Shupe, E. I., Cortina, L. M., Ramos, A., Fitzgerald, L. F., \& Salisbury, J. (2002). The incidence and outcomes of sexual harassment among Hispanic and Non-Hispanic white women: A comparison across levels of cultural affiliation. Psychology of Women Quarterly, 26(4), 298-308. 10.1111/1471-6402.t01-2-00069

Solomon, D. H., \& Williams, M. L. (1997). Perceptions of social-sexual communication at work as sexually harassing. Management Communication Quarterly, 11(2), 147-184. doi: 10.1177/0893318997112001

Stockdale, M. S., Logan, T. K., Sliter, K. A., \& Berry, S. A. (2014). Interpersonal violence victimization and sexual harassment: A prospective study of revictimization. Sex Roles, 71(1-2), 55-70. doi:10.1007/s11199-014-0377-5

Thomas, J., \& Harden, A. (2008). Methods for the thematic synthesis of qualitative research in systematic reviews. BMC Medical Research Methodology, 8(1), 45. doi: 10.1186/1471-2288-8-45

Timmerman, G., \& Bajema, C. (1999). Sexual harassment in northwest Europe: A cross-cultural comparison. European Journal of Women's Studies, 6(4), 419-439. doi: 10.1177/135050689900600402

Timmerman, G., \& Bajema, C. (2000). The impact of organizational culture on perceptions and experinces of sexual harassment. Journal of Vocational Behaviour, 57, 188-205. doi: 10.1006/jvbe.1999.1741

Tinkler, J. E. (2008). People are too quick to take offense: The effects of legal information and beliefs on definitions of sexual harassment. Law and Social Inquiry, 33(2), 417-445. doi: 10.1111/j.1747-4469.2008.00108.x

Vogt, D., Bruce, T. A., Street, A. E., \& Stafford, J. (2007). Attitudes towards women and tolerance for sexual harassment among reservists. Violence Against Women, 13(9), 879-900. doi:10.1177/1077801207305217

Wasti, S. A., \& Cortina, L. M. (2002). Coping in context: Sociocultural determinants of responses to sexual harrassment. Journal of Personality and Social Psychology, 83(2), 394-405. doi:10.1037/0022-3514.83.2.394

Wear, D., Aultman, J. M., \& Borges, N. J. (2007). Retheorizing sexual harassment in medical education: Women students' perceptions at five U.S. medical schools. Teaching and Learning in Medicine, 19(1), 20-29. doi:10.1080/ 10401330709336619

Welsh, S. (1999). Gender and sexual harassment. Annual Review of Sociology, 25, 169-190. doi:10.1146/annurev.soc.25.1.169

Whaley, G. L., \& Tucker, S. H. (1998). A theoretical integration of sexual harassment models. Equal Opportunities International, 17(1), 21-29. doi: 10.1108/ 02610159810785485 
Wiener, R. L., \& Hurt, L. E. (1997). Social sexual conduct at work: How do workers know when it is harassment and when it is not? California Western Law Review, 34(1), 53-97. Retreived from https://scholarlycommons.law.cwsl.edu/cwlr/ vol34/iss $1 / 4$

Wiener, R. L., \& Hurt, L. E. (2000). How do people evaluate social sexual conduct at work? A psycholegal model. Journal of Applied Psychology, 85(1), 75-85. doi: 10.1037/0021-9010.85.1.75

Wiener, R. L., Voss, A. M., Winter, R. J., \& Arnot, L. (2005). The more you see it, the more you know it: Memory accessibility and sexual harassment judgements. Sex Roles, 53(11/12), 807-820. doi:10.1007/s11199-005-8294-2

Wiener, R. L., Winter, R., Rogers, M., \& Arnot, L. (2004). The effects of prior workplace behavior on subsequent sexual harassment judgments. Law and Human Behavior, 28(1), 47-67. doi: 10.1023/B:LAHU.0000015003.72223.63

Wright, C. V., \& Fitzgerald, L. F. (2007). Angry and afraid: Women's appraisal of sexual harassment during litigation. Psychology of Women Quarterly, 31, 73-84. doi: 10.1111/j.1471-6402.2007.00332.x

Yagil, D. (2008). When the customer is wrong: A review of research on aggression and sexual harassment in service encounters. Aggression and Violent Behaviour, 13(2), 141-152. doi: 10.1016/j.avb.2008.03.002

Yoder, J. D., \& Aniakudo, P. (1995). The responses of African American women firefighters to gender harassment at work. Sex Roles, 32(3-4), 125-137. doi: 10.1007/BF01544784

Zimbroff, J. (2007). Cultural differences in perceptions of and responses to sexual harassment. Duke Journal of Gender Law and Policy. 14, 1311-1341. Retrieved from https://scholarship.law.duke.edu/djglp/vol14/iss2/14 